JURNAL PENDIDIKAN, p-ISSN 2715-095X, e-ISSN 2686-5041

Volume 30, No.2, Juli 2021 (219-224)

Online: http://journal.univetbantara.ac.id/index.php/jp

\title{
Best Practice \\ Implementasi Project Based Learning (Improbasle) Pada Pembelajaran Online di Masa Pandemi Covid-19 Bagi Siswa SMA Negeri 1 Tawangsari Tahun Pelajaran 2020/2021
}

\section{Sri Yamsih}

SMA Negeri 1 Tawangsari, Kabupaten Sukoharjo. E-mail: drasriyamsih@gmail.com

Received: March 18, 2021

Accepted: April 24, 2021

Online Published: Juni 26, 2021

\begin{abstract}
Abstrak: Implementasi Project Based Learning pada pembelajaran online di masa pandemi Covid-19 bagi siswa SMA Negeri 1 Tawangsari merupakan model pembelajaran dengan tujuan memberikan kebebasan kepada siswa untuk merencanakan kegiatan belajar, melaksanakan proyek secara kolaboratif dalam memecahkan permasalahan dan pada akhirnya menghasilkan karya nyata yang dapat dipublikasikan kepada orang lain yang dapat dijadikan acuan dalam memecahkan permasalahannya. $P j B L$ merupakan serangkaian kegiatan belajar mengajar yang menuntun siswa untuk dapat melakukan kegiatan/proyek. Langkah-langkah pembelajaran meliputi: penentuan proyek, perancangan langkah-langkah penyelesaian proyek, penyusunan jadwal pelaksanaan proyek, penyelesaian proyek dengan fasilitas dan monitoring guru, presentasi/publikasi hasil produk, evaluasi proses serta hasil proyek. E-Learning merupakan pembelajaran online yang harus dijalani semua siswa SMA Negeri 1 Tawangsari. Pembelajaran online membutuhkan sarana prasarana berupa $\mathrm{hp}$, komputer/laptop, serta jaringan internet. Sekolah mengambil kebijakan dengan memberikan subsidi kouta belajar bagi seluruh siswa beserta bapak/ibu guru. Selain itu seluruh siswa juga mendapat bantuan kuota belajar dari Kemdikbud. Diharapkan pembelajaran daring bisa berlangsung dengan baik.
\end{abstract}

Kata-kata Kunci : Implementasi Project Based Learning.

\section{Implementasi of Project Based Learning (Improbasle) in Online Learning During the Covid-19 Pandemic for Students of SMA Negeri 1 Tawangsari Academic Year 2020/2021}

Sri Yamsih

SMA Negeri 1 Tawangsari, Sukoharjo Regency.E-mail:drasriyamsih@gmail.com

\begin{abstract}
Abstact: Implementation of Project Based Learning (Improbasle) in online learning during the Covid-19 pandemic for SMA Negeri 1 Tawangsari students is a learning model that aims to give students the freedom to plan learning activities, carry out projects collaboratively in
\end{abstract}


solving problems, and ultimately produce real work that can be published to others who can be used as a reference in solving the problem. PjBL is a series of Learning activities that guide students to carry out activities / project. The learning steps include: determining the project, designing the steps for project completion, preparing the project implementation schedule, completing the project with facilities and monitoring the teachers, presenting/publishing product results, evaluating project processes, and result. E-learning is an online learning that all students at SMA Negeri 1 Tawangsari must undergo. Online learning requires facilities and infrastructure in the form of cellphones, computers, / laptop, and internet network. The school makes a policy by providing learning quota assistance for all students and the teachers. In addition, all students also receive learning quote assistance from the Ministry of Education and Culture. It is hoped that online Learning can take place well.

Keywords : Implementation of Project Based Learning.

\section{Pendahuluan}

Keberhasilan pendidikan pada suatu sekolah dipengaruhi oleh dua faktor, yaitu faktor guru dan faktor siswa. Faktor dari guru yaitu cara guru menyampaikan materi pembelajaran. Metode pembelajaran yang digunakan oleh guru masih metode pembelajaran konvensional. Ternyata metode ini kurang optimal untuk meningkatkan pemahaman siswa. Oleh sebab itu perlu menggunakan metode pembelajaran inovatif, yaitu metode pembelajaran $P j B L$. Faktor dari siswa yaitu siswa kurang memahami relevansi konsep dalam kehidupan sehari hari, sehingga mereka kurang tertarik dengan materi yang disampaikan oleh guru.

Selain itu model pembelajaran yang diterapkan membuat siswa kurang aktif serta siswa tidak mampu mengembangkan potensi dan kreatifitasnya. Dengan model pembelajaran inovatif yang dikembangkan untuk mancapai hasil belajar berupa prestasi akademik, dan non akademik. Untuk mencapai hasil belajar itu model pembelajaran $P j B L$ dilaksanakan melalui kegiatan-kegiatan kompleks.

Implementasi pembelajaran $P j B L$ siswa secara aktif terlibat dalam pemecahan masalah yang diberikan guru dalam bentuk suatu kegiatan. Siswa aktif mengelola pembelajaran dengan aktif melakukan kegiatan yang menghasilkan karya nyata. Hasil akhir pembelajaran $P j B L$ dapat menciptakan kompetisi di kelas dan mengarahkan siswa untuk lebih aktif,kreatif serta inovatif. Model pembelajaran $P j B L$ dapatdilaksanakan secara mandiri melalui pengetahuan dan keterampilan baru, serta mewujudkannya dalam karya nyata yang berguna dan bermanfaat.

Penggunaan metode pembelajaran yang variatif mampu membuat siswa lebih tertarik untuk mempelajari semua bidang akademik ataupun non akademik. Salah satu metode pembelajaran yang digunakan adalah dengan metode pembelajaran PjBL.ELearning adalah metode pembelajaran berbasis internet yang harus dijalani seluruh siswa guna menyambung proses belajar tatap muka yang terkendala. Di Indonesia, sistem $e$ learning belum semua sekolah mampu menerapkannya terutama sekolah yang berada di daerah terpencil atau di desa-desa. Pada dasarnya, e-learning memiliki dua jenis yaitu synchronous dan asynchronous. Synchronous berarti pelaksanaan pembelajaran pada waktu 
yang bersama. Dimana proses pembelajaran terjadi pada waktu yang sama antara guru dan siswa. Hal ini dapat memungkinkan interaksi langsung antara guru dengan siswa secara online.

Dalam pelaksanaan, synchronous training mewajibkan guru dan siswa untuk mengakses internet. Guru memberikan materi dalam bentuk slide presentasi serta siswa dapat menyimak secara langsung lewat internet. Siswa juga dapat bertanya secara langsung dan dengan chat dari aplikasi/ web yang digunakan untuk mengajar. Synchronous training adalah gambaran kelas nyata yang bersifat virtual yang dapat diakses melalui internet. Synchronous training disebut juga virtual classroom (Hartanto, 2016). Proses belajar elearning siswa membutuhkan media yang mendukung supaya pembelajaran berlangsung dan memiliki kualitas yang lebih baik (Rustiani,dkk., 2019). Media yang digunakan adalah smartphone (handphone pintar), komputer/laptop, aplikasi, serta jaringan internet dalam pembelajaran e-learning. Akan tetapi, tidak semua orang tua sanggup memenuhi kebutuhan tersebut mengingat status perekonomian yang belum merata. Sehingga proses pembelajaran e-learning tidak tersampaikan dengan baik (Suwarto, 2017). Kurangnya fasilitas membuat anak tidak dapat mengikuti pembelajaran dengan baik (Suwarto, 2009).

Pemaduan antara belajar offline dan online adalah suatu langkah demokratis untuk menyambung penyebaran e-learning yang digunakan dalam ruang kelas. Artinya, elearning belum mampu menggantikan pembelajaran tatap muka karena metode tatap muka lebih efektif dibandingkan dengan pembelajaran online atau e-learning. Selain itu, keterbatasan akses Internet, perangkat keras (hardware) dan perangkat lunak (software), serta pengelolaan sering menjadi kendala dalam belajar online. Penggunaan internet bisa di akses melalui komputer, laptop, $\mathrm{hp}$, tab atau alat komunikasi modern yang lain. Membuktikan bahwa arus komunikasi antara masyarakat satu dengan lainnya telah mengalami kemajuan yang sangat cepat. Salah satunya adalah Youtube. Youtube merupakan media yang menyediakan berbagi video yang sebagian besar manusia didunia mengenal dan menggunakan aplikasi ini. Berbagai situs dan program serta konten video ditampilkan oleh Youtube guna memberikan hiburan serta pengetahuan.

Di dunia pendidikan, Youtube merupakan pilihan baru selain dari media lainnya yang dipakai pada sistem pendidikan. Youtube yang awalnya menyediakan video untuk hiburan sekarang lebih banyak digunakan sebagai media pendidikan. Dimana Youtube yang memiliki bermacam-macam unggahan video yang bisa dimanfaatkan bagi siapa saja baik itu guru, siswa, stap sekolah bahkan orang tua dapat menggunakan Youtube dalam mencari sumber yang dibutuhkan. Youtube menjadi media pembelajaran yang sangat di butuhkan saat ini. Youtube dapat dipergunakan untuk merangsang pikiran, perasaan, perhatian dan kemampuan siswa sehingga dapat mendorong terjadinya proses belajar. Youtube merupakan tantangan bagi seorang guru untuk dapat lebih kreatif dan inovatif dalam memberikan materi pembelajaran begitu juga bagi siswa. Youtube dapat memberikan gambaran dan pemahaman materi dari isi materi yag di sajikan dalam Youtube dari berbagai narator dan kreator video.

\section{Metode Penelitian}

PjBL merupakan metode pembelajaranyang menuntun siswa untuk melaksanakan kegiatan/proyek. Tahapan pembelajaran meliputi: penentuan proyek, perencanaan tahap 
penyelesaian proyek, pembuatan jadwal pelaksanaan proyek, penyelesaian proyek dengan fasilitas dan monitoring guru, presentasi/publikasi hasil produk, evaluasi proses dan hasil produk.

\section{Hasil Penelitian dan Pembahasan}

PjBL merupakan metode pembelajaran yang menuntun siswa untuk melaksanakan kegiatan melalui prosedur pembelajaran yang meliputi: pengamatan (observasi), wawancara atau tanya jawab, menggali ilmu secara mandiri, eksperimen (pengamatan), investigasi, kerjasama atau kolaborasi dalam satu kelompok diskusi, eksplorasi, penilaian, interpretasi hingga presentasi hasil pembelajaran. $P j B L$ mempunyai karakteristik sebagai berikut: (1) Siswa menjadi obyek yang aktif belajar pada proses pembelajaran. (2) Kegiatan yang direncanakan sesuai dengan indikator pada proses pembelajaran (3) Proyek dikembangkan dengan beberapa -pertanyaan sebagai kerangka dari kurikulum (curriculumframing question). (4) Proyek melibatkan jenis dan bentuk penilaian yang dilaksanakan secara kontinyu (on going asessment). (5) Kegiatan yang dilakukan berhubungan langsung dengan dunia nyata. (6)Siswa membuktikan pengetahuannya melalui hasil kerja. (7) Teknologi membantu dan menumbuhkan kemampuan belajar siswa. (8) Keterampilan berpikir terpadu dalam proyek/kegiatan. (9) Metode pembelajaran bervariasi untuk mendukung model belajar yang dimiliki oleh siswa. PjBL merupakan metode pembelajaran yang memanfaatkan masalah sebagai langkah awal dalam mengumpulkan dan mengintegrasikan pengetahuan baru berdasarkan pengalamannya dalam melakukan karya nyata.

\section{Simpulan dan Saran}

(1) Implementasi PjBL bagi siswa di SMA Negeri 1 Tawangsari. Dengan menerapkan pembelajaran $P j B L$, siswa dituntut aktif dalam proses pembelajaran. Siswa akan merasakan langsung dalam mengembangkan pembelajaran, mendapatkan pengetahuan. Hal ini dikarenakan siswa terlibat langsung dalam pencarian informasi atau materi pembelajaran dengan kegiatan yang kontekstual. Siswa diajak melakukan pengamatan atau observasi, penelitian, diskusi kelas, serta melakukan presentasi. Siswa dituntut berpikir kreatif serta inovatif dalam melakukan pemecahan masalah yang dibahas pada pembelajaran berbasis proyek. Tahap PjBL adalah sebagai berikut: (a) Penetapan proyek. (b) Perencanaan tahapan penyelesaian proyek. (c) Penyusunan jadwal pelaksanaan proyek. (d) Penyelesaian proyek melalui fasilitas serta monitoring guru. (e) Presentasi/publikasi hasil produk. (f) Evaluasi proses serta hasil proyek.

(2) Pembelajaran online di masa pandemi Covid-19 bagi siswa di SMA Negeri 1 Tawangsari. E-Learning adalah pembelajaran online yang dijalani semua siswa di SMA 
Negeri 1 Tawangsari bahkan seluruh dunia guna menyambung pembelajaran tatap muka yang terkendala. Proses pembelajaran online membutuhkan media pembelajaran seperti hp, komputer/ laptop, serta jejaring internet. Namun, belum semua orang tua dapat memenuhi sarana prasana tersebut mengingat status perekonomian yang belum merata. Sampai kini sistem pembelajaran online belum tersampaikan dengan baik. Kurangnya fasilitas membuat siswa belum mampu mengikuti pembelajaran sebagaimana mestinya. Sekolah mengambil kebijakan dengan memberikan subsidi kouta belajar bagi seluruh siswa beserta bapak/ibu guru. Selain itu seluruh siswa juga mendapat bantuan kuota belajar dari Kemdikbud. Diharapkan pembelajaran secara online bisa berlangsung dengan baik.

Pada realisasi pembelajaran $P j B L$ yang dilaksanakan bagi siswa di SMA Negeri 1 Tawangsari masih ditemukan beberapa hal yang perlu ditingkatkan agar pelaksanaan pembelajaran benar-benar sesuai dengan konsep pembelajaran berbasis proyek/kegiatan. Dalam penyusunan kelompok kerja siswa, guru harus memetakan kompetensi-kompetensi siswa terlebih dahulu, agar dalam aktivitas pembelajaran tidak terjadi kesenjangan antara kelompok kerja siswa satu dengan yang lain.

\section{Daftar Rujukan}

Briliannur Dwi C, Aisyah Amelia, Uswatun Hasanah, Abdy Mahesha Putra, Hidayatur Rahman. (2020). Analisis Keefektifan Pembelajaran Online di Masa Pandemi Covid-19. Jurnal Pendidikan Guru Sekolah Dasar, volume 2(1): 28-37.

Dinita Mubianti. (2020). Perencanaan E-Learning Masa Pandemi Covid-19. https://www.kompasiana.com/dinita33308/5fd98d6ad541df061016a225/perencanaa n-e-learning-masa-pandemi-covid-19 (di akses: 7 Maret 2020).

Dwi Puji Astuti, Siswandari,Djoko Santoso. (2017). E-Book for Problem Based Learning to Improve Learning Outcome of the Students. Advances in Social Science, Education and Humanities Research (ASSEHR), volume 15(8): 220-227.

Dwi Sulisworo. (2020). Praktik Pembelajaran Online Era Covid-19. Yogyakarta: CV Markumi.

Hamidi Ahmad. (2020). Workshop Efektivitas Pembelajaran Daring Pada Masa Pandemi Covid-19 Di Prodi IKOR. Jurnal Maenpo: Jurnal Pendidikan Jasmani Kesehatan dan Rekreasi, volume 10(2): 109-118.

Hani Abdul. (2020). Strategi Penggunaan E-Learning Sebagai Media Pembelajaran Di Masa Pandemi Covid-19.Jurnal Agriwidya, volume 1(3): 3-10.

Indy Kumalasari. (2014). Pendekatan Saintifik. https://www.slideshare.net/indykumalasari/ 10-pendekatansaintifik (di akses: 8 Maret 2020).

Mulyani Sri. (2020). Peningkatan Hasil Belajar Biologi Materi Sistem Pernafasan Melaui Model Problem Based Learning Bagi Peserta Didik Kelas XI MIPA 6 SMA Negeri 1 Tawangsari Semester 2 Tahun Pelajaran 2017/2018. Jurnal Pendidikan, volume 29(2): 143-150. 
Nurfitriyanti, Maya. (2016). Model Pembelajaran Project Based Learning Terhadap Kemampuan Pemecahan Masalah Matematika. Jurnal Formatif, volume 6(2): 149-160.

Suwarto, S. (2009). Pengembangan tes dan analisis hasil tes yang terintegrasi dalam program komputer. Jurnal Penelitian dan Evaluasi Pendidikan, 13(1), 40-56.

Suwarto, S. (2017). Pengembangan tes ilmu pengetahuan alam terkomputerisasi. Jurnal Penelitian dan Evaluasi Pendidikan, 21(2), 153-161.

Teach, Intel (2007). Modul Pelatihan Intel Teach-Getting Started, Intel Education.

Teach, Intel (2008). Modul Pelatihan Intel Teach-Essentials Course, Intel Education.

The George Lucas Educational Foundation.(2005).Instructional Module Project Based Learning.

Winarno Agung \& Maulana Afidzatul. (2020). The Implementation of Project Based Learning (PjBL) Based on STEM: A Reflection of Concept and Reality Within Learning Process in Business Department of Vocational High School. Jurnal Pendidikan Bisnis dan Manajemen, volume6(2): 78-86. 